\title{
The clinical implications of the systemic inflammatory reaction related to cardiac operations in children
}

\author{
Marie-Christine Seghaye \\ Department of Paediatric Cardiology and Congenital Cardiac Diseases, Deutsches Herzzentrum an der Technischen \\ Universität München, Germany
}

$\mathrm{T}$ HE PURPOSE OF MY REVIEW IS TO PRESENT THE current knowledge of the impact of the systemic inflammatory response on morbidity following cardiac surgery in children. In the first section, I describe the general principles of the systemic inflammatory response; in the second I consider the impact of cardiac surgery on the systemic inflammatory response. In the third section, I present examples illustrating the relevance of the systemic inflammatory response for postoperative morbidity in children. In the fourth section, I review therapeutic strategies to reduce the inflammatory response to cardiac surgery, and hence postoperative morbidity. Finally, in the last section, I discuss the influence of the preoperative condition on the systemic inflammatory reaction to cardiac surgery.

The systemic inflammatory response: general principles

Systemic inflammation is the non-specific physiological response to a large variety of stimuluses. The systemic inflammatory response caused by bacterial or viral infections is the classical example for this. Systemic inflammation, however, is also elicited by non-infectious stimuluses. Ischemia and re-perfusion, trauma, endotoxaemia, and virtually all situations allowing contact between blood components of an individual and foreign surfaces are inflammatory stimuluses.

Correspondence to: Prof. Marie-Christine Seghaye, Department of Paediatric Cardiology and Congenital Cardiac Diseases, Deutsches Herzzentrum an der Technischen Universität München Lazarettstrasse 36; D-80636 München, Germany. Tel: +4989 1218 3011; Fax: +49 891218 3013; E-mail: seghaye@ dhm.mhn.de

Accepted for publication 15 January 2003
Initiation and termination of the systemic inflammatory response

The blood, the liver and the brain are probably the most important organs controlling initiation and termination of the systemic inflammatory reaction. ${ }^{1,2}$

The complement system is involved early in the complex process of inflammation. Like the systems underscoring coagulation, contact with plasma, and fibrinolysis, with which it has numerous interactions, it is activated in the fashion of a cascade.

The complement system may be activated by one of two pathways, the classical and the alternative, or by both. The classical pathway is mainly activated by antigen-antibody complexes, whereas the alternative pathway is activated by polysaccharides and polymers, such as those found in the cell membrane of microorganisms or those utilised for the fabrication of medical artificial surfaces. The activation of either pathway leads to the formation of $\mathrm{C} 3$-convertase, which activates $\mathrm{C} 3$, a key protein of the terminal sequence of the complement system. The split products of this activation are $\mathrm{C} 3 \mathrm{a}$ and $\mathrm{C} 3 \mathrm{~b}$. $\mathrm{C} 3 \mathrm{a}$ is a potent anaphylatoxin. $\mathrm{C} 3 \mathrm{~b}$ is part of the $\mathrm{C} 3$-convertase of the alternative pathway, and of C5-convertase, which is common to both pathways. C5-convertase activates $\mathrm{C} 5$, the split products of which are $\mathrm{C} 5 \mathrm{a}$ and $\mathrm{C} 5 \mathrm{~b} . \mathrm{C} 5 \mathrm{a}$ is the most potent anaphylatoxin. C5b, by binding the complement proteins $\mathrm{C} 6$ to $\mathrm{C} 9$ forms the terminal complex, also called the membrane attack complex. ${ }^{3}$ The process of activation of complement through either pathway, leading to the formation of the membrane attack complex, is shown in Figure 1.

The biologically active peptides released into the circulation (Table 1) increase vascular permeability, cause vasoconstriction, and lead to formation of oedema. In addition, they activate leukocytes, stimulate phagocytosis, and cause cytolysis. 


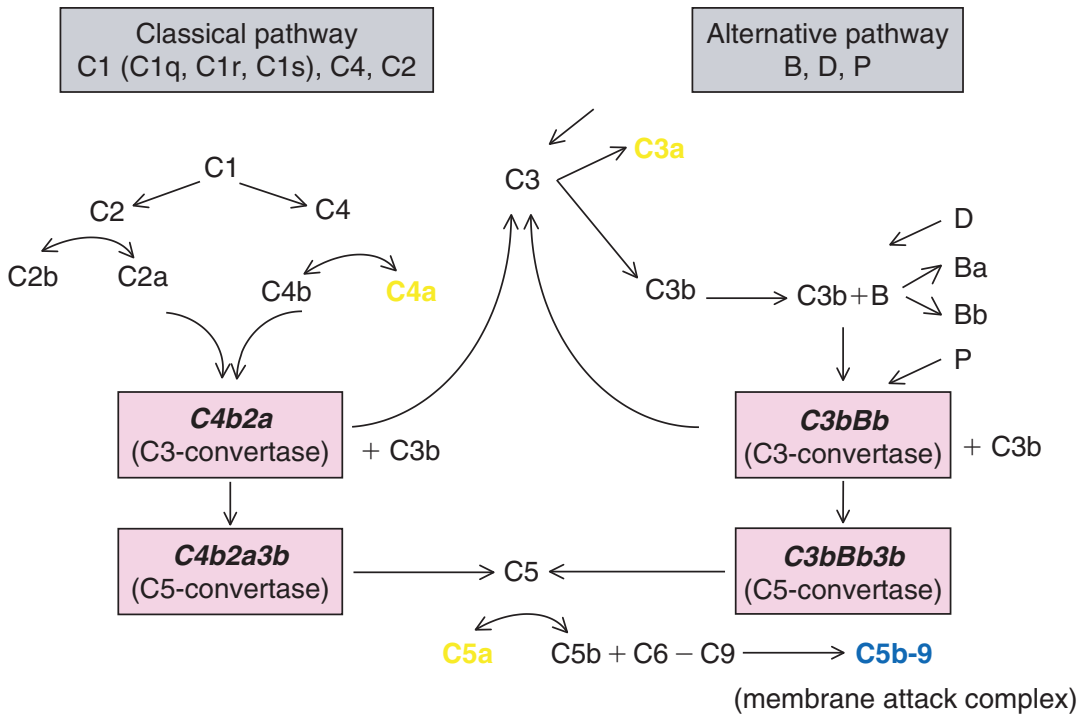

Figure 1.

The complement cascade can be activated throughout either the classical or the alternative pathways. The activation of the classical pathway begins with the binding of an activator to C1, which is composed of 3 portions C1q, C1r and C1s. C1 activates in turn C2 and C4, which are split into $C 2 a, C 2 b$ and $C 4 a, C 4 b$, respectively. The split products $C 2 a$ and $C 4 b$ bind to form the $C 3$-convertase of the classical pathway.

The activation of the alternative pathway probably depends upon cleavage of small amounts of $C 3$ in $C 3 a$ and $C 3 b . C 3 b$ is then available for binding factor $B$. Factor $D$ cleaves bound factor $B$ to produce $B a$ and $B b$. The complex $C 3 b B b$ is the C3-convertase of the alternative pathway that is stabilised by factor $P$, also called properdine.

Both C3-convertases cleave C3 into C3a and C3b. By binding an additional C3b, both C3-convertases become C5-convertases. The cleavage of C5 produces C5a and C5b. C5b bounds C6 and in a stepwise fashion, C7, C8 and C9 are added into the complex to form the so called membrane attack complex. The main molecules with biological properties are represented in red (anaphylatoxins) and in blue (membrane attack complex).

Table 1. Biological properties of the main components of the complement system.

\begin{tabular}{|c|c|c|c|}
\hline Component & Pathway & $\begin{array}{l}\text { Main cleavage } \\
\text { products }\end{array}$ & Main biological properties \\
\hline $\mathrm{C} 1$ & Classical & & Binding to antibodies or other activators; Activation of $\mathrm{C} 4$ and $\mathrm{C} 2$. \\
\hline $\mathrm{C} 4$ & Classical & $\mathrm{C} 4 \mathrm{a}$ & $\begin{array}{l}\text { Anaphylatoxin: increase of vascular permeability, vasoconstriction, mast cell } \\
\text { degranulation with release of histamine. }\end{array}$ \\
\hline B & Alternative & $\mathrm{Ba}$ & Chemotactic. \\
\hline D & Alternative & & Activates B. \\
\hline $\mathbf{P}$ & Alternative & & Stabilises $\mathrm{C} 3 \mathrm{bBb}$ (C3-convertase). \\
\hline \multirow[t]{2}{*}{$\mathrm{C} 3$} & Terminal & $\mathrm{C} 3 \mathrm{a}$ & $\begin{array}{l}\text { Anaphylatoxin: increase of vascular permeability, vasoconstriction, mast cell } \\
\text { degranulation with release of histamine. } \mathrm{C} 3 \mathrm{a} \text { is a more potent anaphylatoxin than C4a. }\end{array}$ \\
\hline & & $\mathrm{C} 3 \mathrm{~b}$ & $\begin{array}{l}\text { Part of the } \mathrm{C} 3 \text {-convertase of the alternative pathway and also of the } \mathrm{C} 5 \text {-convertases of } \\
\text { the classical and the alternative pathway. }\end{array}$ \\
\hline \multirow[t]{2}{*}{$\mathrm{C} 5$} & Terminal & $\mathrm{C} 5 \mathrm{a}$ & $\begin{array}{l}\text { Anaphylatoxin: increase of vascular permeability, vasoconstriction, mast cell } \\
\text { degranulation with release of histamine. In addition, increases neutrophil mobilisation } \\
\text { (chemotaxis) and adhesion. C5a is a more potent anaphylatoxin than C3a. }\end{array}$ \\
\hline & & $\mathrm{C} 5 \mathrm{~b}$ & Part of the membrane attack complex. \\
\hline $\mathrm{C} 6, \mathrm{C} 7, \mathrm{C} 8, \mathrm{C} 9$ & Terminal & & Part of the membrane attack complex; Cytolysis. \\
\hline C1-inhibitor & Control system & & Inhibitor of $\mathrm{C} 1$. \\
\hline
\end{tabular}

Nomenclature: The proteins of the classical pathway and of the terminal sequence are termed "components" (C ) and are given a number from 1 to 9. The proteins of the alternative pathway are represented by a letter (B, D, P). The split products are indicated by a lower case letter (i.e. C3a) (3).

Leukocytes, which are major targets for activated complement proteins, contribute to sustain systemic inflammation. Upon stimulation, they release products of degranulation such as elastase, myeloperoxydase and histamine, and synthesise new inflammatory mediators, such as cytokines. Beside activated complement proteins, ${ }^{4}$ classical stimuluses for expression of cytokine genes are bacterial endotoxin, hypoxia, ${ }^{5,6}$ and cytokines themselves. ${ }^{6}$

Cytokines are small, non-constitutive, peptides that can be produced by virtually all nucleated cells. They have important physiological functions, as 


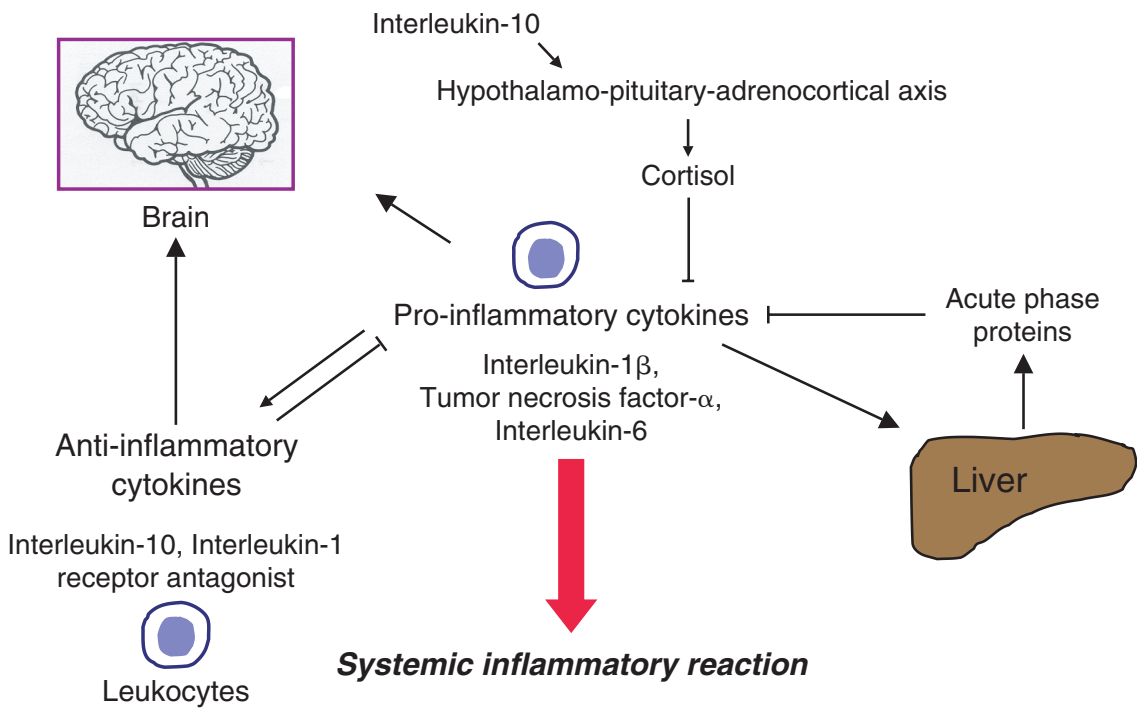

Figure 2.

Upon inflammatory stimulation, nucleated cells produce mediators to which belong the pro-inflammatory cytokines interleukin-1 $\beta$, tumor necrosis factor- $\alpha$ and interleukin- 6 . These cytokines are responsible for the development of the systemic inflammatory reaction. By inducing the acute phase response in the liver, and the synthesis of anti-inflammatory cytokines such as interleukin-10 and interleukin-1 receptor antagonist, pro-inflammatory cytokines limit their own production. Interleukin-10 activates the hypothalamo-pituitaryadrenocortical axis and leads to release of cortisol, which in turn contributes to terminate the inflammatory process. they regulate intercellular interactions and cell growth. As far as inflammation is concerned, and based on their biological properties, cytokines can be divided into pro- and anti-inflammatory groups. ${ }^{7,8}$

Pro-inflammatory cytokines have biological properties that relate to the stimulation of leukocytes, endothelial cells and virtually all parenchymatous cells, causing them to produce other inflammatory mediators, cytotoxicity, and initiation of cell death. ${ }^{7,9}$ Cell death, in both its necrotic and apoptotic forms, will be discussed in detail later. Tumour necrosis factor- $\alpha$ and interleukin- $1 \beta$, are so-called early pro-inflammatory cytokines because they are immediately up-regulated in response to an inflammatory stimulus. They initiate systemic inflammation and, because of their pyrogenic properties, they elicit the febrile response. ${ }^{1,10}$ Interleukin- 6 is another important pro-inflammatory cytokine, as it is the principal regulator of the acute phase response. ${ }^{1}$ It stimulates the intrahepatic synthesis of acute phase proteins, such as $\mathrm{C}$-reactive protein. This is a central step for the termination of the systemic inflammatory reaction, since acute phase proteins possess anti-inflammatory properties. ${ }^{11}$

The natural anti-inflammatory response to an injury is mediated by anti-inflammatory cytokines, such as interleukin-10 and the interleukin-1 receptor antagonist. The appearance of these cytokines in the circulation is normally delayed compared to that of pro-inflammatory mediators, from which their synthesis, in part, depends. Interleukin-6, in later states of inflammation, also has anti-inflammatory properties, since it up-regulates interleukin-1 ra and interleukin-10. ${ }^{12,13}$

Anti-inflammatory cytokines inhibit the synthesis of pro-inflammatory cytokines. ${ }^{14}$ By activating the hypothalamo-pituitary-adrenal axis, they stimulate release of cortisol, and thence stop the systemic inflammatory response. ${ }^{2,12}$ The principal mechanisms involved in the initiation and termination of the acute systemic inflammatory response are shown in Figure 2, whilst Table 2 summarises the biological properties of the principal cytokines involved in systemic inflammation.

\section{Nuclear factor kappa B: the key transcription factor of many inflammatory genes}

Nuclear factor kappa B plays a central role in inflammation, as it is the main transcription factor for inflammatory mediators, including pro-inflammatory cytokines such as tumour necrosis factor- $\alpha$, interleukin-1 $\beta$, and interleukin- 6 , chemokines such as interleukin-8, inflammatory enzymes such as inducible nitric oxide synthase, inducible cyclooxygenase, 5-lipoxygenase, and phospholipase A2, and adhesion molecules such as intercellular adhesion molecule-1, vascular-cell adhesion molecule-1, and E-selectin.

Nuclear factor kappa B is a heterodimer comprising two subunits, $\mathrm{p} 50$ and $\mathrm{p} 65$. In the normal state, it is bound to its natural inhibitory protein, inhibitory kappa $\mathrm{B}$, which prevents it entering the nucleus. ${ }^{6}$ Upon stimulation, inhibitory kappa B becomes phophorylated and degraded. Nuclear factor kappa B is then allowed to translocate into the nucleus, where it regulates the transcription of inflammatory proteins. ${ }^{6}$ Since many inflammatory proteins controlled by Nuclear factor kappa B act as activators of this transcription factor, there is an amplifying loop of inflammation (Fig. 3).

\section{The inflammatory damage to tissues and organs}

The inflammatory damage to tissues involves complex mechanisms characterised by the activation of leukocytes, platelets, endothelial, and parenchymal cells. ${ }^{15}$ 
Table 2. Biological properties of the main pro- and anti-inflammatory cytokines involved in the pathophysiology of inflammation in the setting of cardiac surgery.

\begin{tabular}{lll}
\hline Cytokine & Classification & Stimuluses \\
\hline Tumor necrosis & Pro-inflammatory & $\begin{array}{l}\text { Endotoxin; Activated } \\
\text { complement; Hypoxia; }\end{array}$ \\
factor- $\alpha ?$ & Other pro-inflammatory & cytokines
\end{tabular}

Interleukin-1 $\beta$

Pro-inflammatory cytokine

Pro- and also anti-inflammatory cytokine

Interleukin-8

Interleukin-10

Interleukin-1 receptor antagonist
Pro-inflammatory cytokine

Anti-inflammatory cytokine

Anti-inflammatory cytokine

\section{Biological properties}

Primary (early) mediator of inflammation; Pyrogen; Inductor of acute phase reaction; up-regulates complement proteins; Activates nuclear factor kappa B and hereby leads to up-regulation of many inflammatory genes comprising the inducible nitric oxide synthase; Procoagulant activity; Produces cytotoxicity and initiates cell death (necrosis and apoptosis); Leads to vasodilation, increased vascular permeability, interstitial oedema, micro-infarctions, leukocyte plugging;

Cardiodepressant (reduces systolic and diastolic myocardial function); Major mediator in septic shock

Primary (early) mediator of inflammation; Pyrogen; Inductor of acute phase reaction; up-regulates complement proteins; Activates nuclear factor kappa B and hereby leads to up-regulation of many inflammatory genes comprising the inducible nitric oxide synthase; Procoagulant activity; Cardiodepressant; Pyrogenic; Acts synergistically with tumor necrosis factor- $\alpha$

Pro-inflammatory cytokines; Hypoxia.

Later mediator of inflammation; Major regulator of the acute phase response; Stimulates the intrahepatic synthesis of acute phase proteins such as $\mathrm{C}$-reactive protein

Anti-inflammatory properties at later stage of inflammation by up-regulation of Interleukin-1 receptor antagonist and Interleukin-10

Later mediator of inflammation; Chemokine (leukocyte chemotactic factor); Regulates leukocyte recruitment and increases leukocyte-endothelium interactions

Late mediator of inflammation; Macrophage inhibitor; Inhibits the production of pro-inflammatory cytokines and chemokines as well as its own production; Promotes the release of Interleukin-1 receptor antagonist; Organ protective

Antagonises interleukin-1 cytokines; Hypoxia-hyperoxia cytokines

Endotoxin; Tumor necrosis factor- $\alpha$ and other pro-inflammatory Pro-inflammatory cytokines

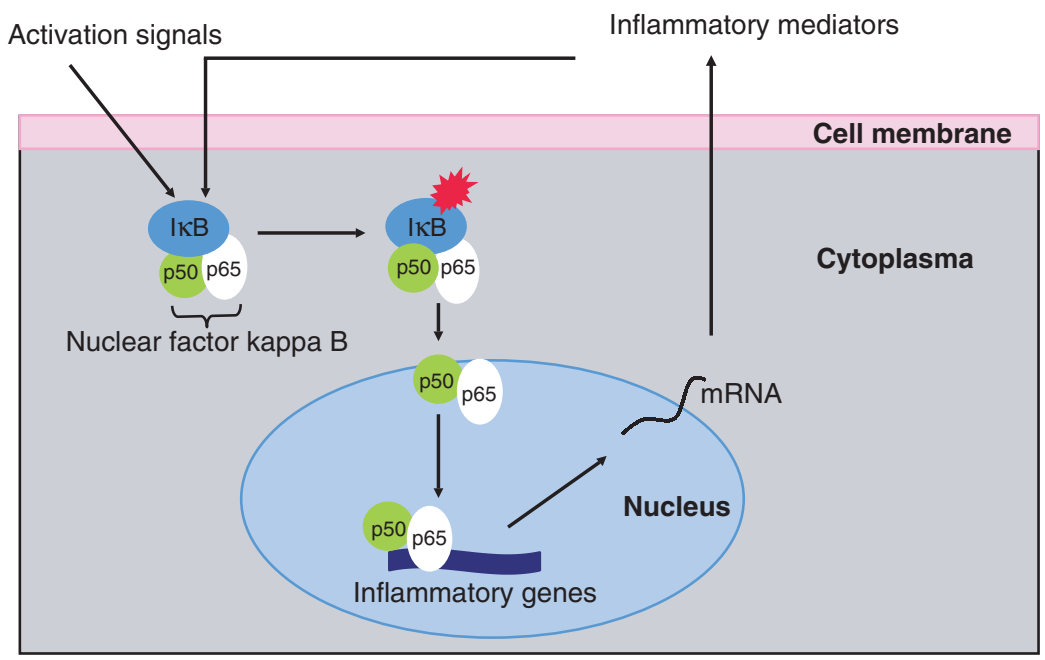

Figure 3.

Nuclear factor kappa $B$ is the main transcription factor of inflammatory genes. Under normal conditions, nuclear factor kappa B, a beterodimer consisting of two sub-units, $p 50$ and p65, is bound to its inbibitory protein inbibitory kappa B. Upon stimulation, this inbibitory protein undergoes phophorylation, and thereby degradation. Nuclear factor kappa $B$ is then allowed to translocate into the nucleus, where it regulates the transcription of inflammatory genes such as pro-inflammatory cytokines, adhesion molecules, and the inducible nitric oxide synthase. Since the proteins resulting from the activity of nuclear factor kappa B are in turn its activators, an amplifying loop ensues that may lead to uncontrolled inflammation. 


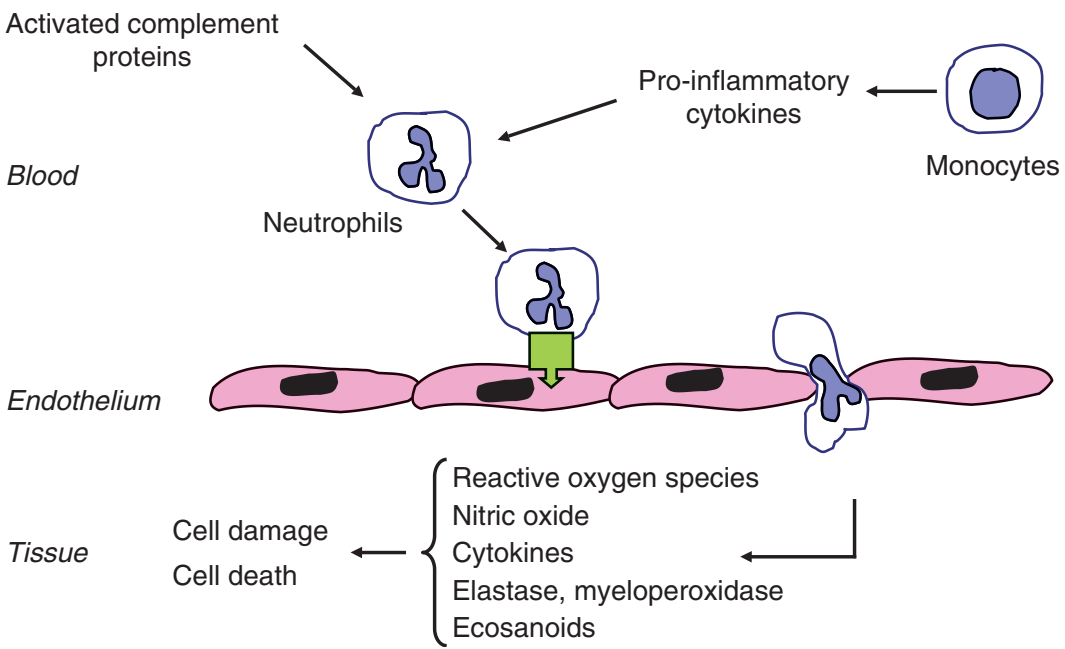

Figure 4.

The inflammatory damage to tissues is related to the activation of leukocytes by circulating mediators such as activated complement proteins and pro-inflammatory cytokines. Activated leukocytes express adhesion molecules (green arrow), which are necessary to achieve interactions between lenkocytes and endothelial cells. This results in a decrease in the velocity of lenkocytes in the blood vessel, in firm adhesion of leukocytes onto the endothelium, and finally in transmigration of lenkocytes into the interstitial tissue, where they release toxic degranulation products, which in turn are responsible for damage to and death of cells.
Independent of the local or systemic character of inflammation, activated complement proteins, and pro-inflammatory cytokines, lead to the synthesis of adhesion molecules by activating Nuclear factor kappa B. ${ }^{6}$ Adhesion molecules act to increase leukocyte-endothelium interactions in a 3-stage process. First, due to the expression of E-(endothelial) and L-(leukocyte)-selectins, leukocytes move slowly on the endothelium and begin to roll on it. In the second phase, integrins such as the complement receptor-3 (CD11b/CD18) expressed on neutrophils lead to the firm adhesion of the leukocytes by binding activated adhesion molecules such as intercellular adhesion molecule- 1 on endothelial cells. This step is related to leukocyte degranulation and respiratory burst, and thereby to the release of cytotoxic enzymes which damage the endothelium and the surrounding tissues. In the third stage, the activated neutrophils transmigrate into the interstitial tissues, ${ }^{15,16}$ where they release radical oxygen species, nitric oxide, inflammatory enzymes and newly synthesised cytokines, all of which act on parenchymal cells, leading to damage and death of the cells by necrosis or apoptosis (Fig. 4).

From the stance of inflammation itself, it is crucial to differentiate these two different pathways for death of cells. Necrosis involves the loss of integrity of the cell membrane, and therefore is associated with the release of inflammatory products into the interstitium. It contributes to the damage of the neighbouring cells, which will also enter the pathway of death. Necrosis does not require any energy. ${ }^{17}$ Apoptosis, in contrast, is a highly genetically controlled pathway, also known as programmed cell death. Apoptosis is characterised by maintenance of the integrity of the cell membrane, and by shrinkage of the cell, which will be phagocytosed by macrophages. For this reason, apoptosis is non-inflammatory and a self-limiting form of death, which does not cause damage to neighbouring cells and tissues. Apoptosis requires energy. ${ }^{17,18}$

\section{Pro-inflammatory cytokines and organ dysfunction}

Systemic or parenchymatous production of proinflammatory cytokines, such as tumor necrosis factor- $\alpha$ is related to vasodilation, increased vascular permeability, interstitial oedema, and microinfarctions due to leukocyte plugging. These activities lead to hypoperfusion of the tissues and loss of the function of the organ. ${ }^{19-21}$

As far as the myocardium is concerned, tumor necrosis factor- $\alpha$ acts as a cardiodepressant cytokine. It leads to disruption in the handling of calcium, desensitises the myofilaments to calcium, and decreases $\beta$-adrenoceptor responsiveness. 9 The depression of cardiac function in response to tumor necrosis factor- $\alpha$ is biphasic. The immediate contractile dysfunction following administration of tumour necrosis factor- $\alpha$ is mediated by sphingosine, a phospholipid metabolite, while the delayed and sustained systolic and diastolic dysfunction is the result of the activation of inducible nitric oxide synthase. This leads to the production of high, non-physiological, concentrations of nitric oxide. ${ }^{9}$

\section{The balance between the production of pro- and anti-inflammatory cytokines}

Natural anti-inflammatory cytokines, such as interleukin-10, play a central role in the control of systemic inflammation. Protection of organs is likely to depend on the aptitude to produce anti-inflammatory cytokines in response to inflammatory stress. ${ }^{12}$ Indeed, in the setting of sepsis, a higher ratio of the circulating levels of interleukin- 6 to interleukin-10 is a predictor of poor outcome. ${ }^{22}$ Conversely, in infants undergoing 
cardiac surgery, a higher ratio between circulating levels of interleukin-10 and interleukin-6 is associated with less postoperative morbidity. ${ }^{23}$ Our own experimental data clearly indicate that greater production of interleukin-10 during cardiac surgery is associated with protection of the organs. ${ }^{24,25}$

The potential for the anti-inflammatory cytokine response is probably multifactorial. Factors influencing this potential are:

- A genetic predisposition due to the presence of different polymorphisms for pro- and antiinflammatory cytokines. ${ }^{26}$

- Gender, as female sexual hormones could modify the anti-inflammatory response. ${ }^{27}$

- Preoperative conditions such as heart failure and/or hypoxaemia which lead to systemic and intramyocardial inflammation. ${ }^{28,29}$

- Drug treatments such as corticosteroids, phosphodiesterase inhibitors or $\beta$-agonists, which shift the cytokine balance toward a net anti-inflammatory cytokine production. ${ }^{30-32}$

While an adequate anti-inflammatory reaction is necessary to control systemic inflammation, the question as to whether excessive levels of interleukin-10 after cardiac surgery could harm by initiating immune paralysis, therefore increasing the risk of postoperative infection, has yet to be answered. ${ }^{33}$ Indeed, in patients with severe sepsis or trauma, it has been shown that an hypo-inflammatory state follows the early phase of uncontrolled inflammation. This hypoinflammatory state is related to deactivation of monocytes, with decreased activation of nuclear factor kappa B. Although the circulating levels of interleukin-10 do not correlate with the degree of monocytic activation, they still remain elevated up to 10 days after the acute inflammatory event, suggesting that sustained production of anti-inflammatory cytokine is, at least in part, responsible for the immune paralysis observed. ${ }^{34,35}$ This points out the importance of understanding the exact mechanisms regulating the inflammatory balance, permitting both the control of the systemic inflammation and maintenance of immune competence.

\section{The impact of paediatric cardiac surgery on the systemic inflammatory reaction}

More than twenty years ago, Chenoweth and his group $^{36}$ first reported the activation of the complement system during cardiopulmonary bypass in adults. Two years later, Kirklin ${ }^{37}$ demonstrated the positive relationship between activation of complement and postoperative morbidity in adults and in children. Since then, great efforts have been made to define better the mechanisms involved in the systemic inflammatory reaction associated with cardiac surgery. It is widely accepted today that the contact between blood and foreign surfaces during cardiopulmonary bypass initiates the activation of the alternative pathway of the complement system. ${ }^{36-38}$ At the end of cardiopulmonary bypass, activation of complement is enhanced by heparin-protamine complexes that act on the classical pathway. ${ }^{39}$

The complement system has many interactions with the contact system of the plasma, with the coagulation system, and with the system of fibrinolysis. All of them are activated in the setting of cardiac surgery. ${ }^{40}$ Together, they contribute to sustain systemic inflammation. Activated complement proteins influence leukocytic function by stimulating mobilisation, adhesion, and degranulation of the leukocytes, and also synthesis of cytokines. ${ }^{6,41}$ The principal mechanisms involved in the pathophysiology of cardiopulmonary bypass are shown in Figure 5.

\section{Contact blood/artificial surfaces $\quad$ Ischemia and reperfusion}

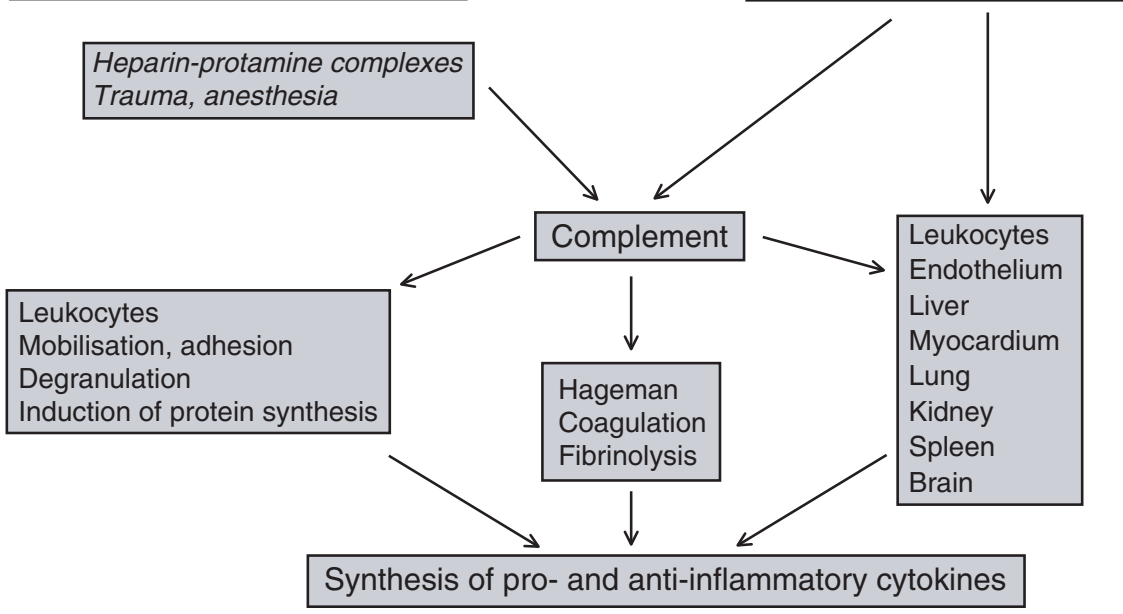

Figure 5.

Cardiac operations involving cardiopulmonary bypass are associated with a systemic inflammatory reaction due, in the first instance, to the contact between blood and artificial surfaces, resulting in activation of the complement system. This is enhanced by ischemia followed by reperfusion of the organs, and by the activation of the Hageman system, along with the coagulative and the fibrinolytic cascades. Activated complement proteins, ischemia, and reperfusion are among others inducers of leukocytic activation and synthesis of pro-inflammatory cytokines, which contribute to the synthesis of anti-inflammatory cytokines. 


\section{Activation of complement}

Neonates and young children undergoing cardiac surgery with cardiopulmonary bypass show significant C3- and C5-conversion, ${ }^{37,42-44}$ indicating late phase activation of the complement system up to the terminal membrane attack complex. Significant activation of complement is observed as early as 10 minutes after institution of cardiopulmonary bypass, and the peak value of circulating activated complement proteins is observed at the end of cardiopulmonary bypass. ${ }^{43}$ By this time, several simultaneous events have taken place, including the reinstitution of myocardial perfusion, the rewarming of the patient, and the administration of protamine, all factors that sustain activation of complement. ${ }^{39,45,46}$

\section{Leukocytic activation}

The importance of leukocytic activation in causing damage to the tissues during cardiac surgery in children is underscored by studies showing improved myocardial function in piglets treated with an inhibitor of Complement receptor-3 (CD11b/CD18) up-regulation on leukocytes. ${ }^{47}$ In addition to that, the magnitude of release of elastase or histamine from activated leukocytes observed during cardiac surgery in neonates and children has clearly been associated with the development of postoperative complications. ${ }^{43,48}$

\section{Synthesis of cytokines}

Neonates, infants and children undergoing cardiac operations with cardiopulmonary bypass show significant production of pro-inflammatory cytokines, such as tumor necrosis factor- $\alpha$ interleukin- 6 , and interleukin-8. ${ }^{49}$ There is also a significant production of interleukin-10, ${ }^{50,51}$ indicating the potential for the anti-inflammatory response. Usually, concentrations of tumour necrosis factor- $\alpha$, interleukin-6, and interleukin- 8 reach maximal values in the plasma at the end of cardiopulmonary bypass, while those of interleukin-10 are measured either at the end of cardiopulmonary bypass, ${ }^{52}$ or later on the first postoperative day. ${ }^{50}$ The precise time depends on the perioperative management, including among others, pretreatment with corticosteroids, ${ }^{30}$ and the degree of hypothermia achieved during cardiopulmonary bypass. $^{50}$

Complement anaphylatoxins, ${ }^{41}$ and endotoxin released from the gut, ${ }^{53}$ are thought to be the major triggers for pro-inflammatory production of cytokines during cardiac surgery in children. Other mechanisms, such as hypoxia and reoxygenation, ${ }^{54}$ and operative trauma, ${ }^{55}$ probably also play an important role.

\section{Clinical implications of the systemic inflammatory reaction related to cardiac operations}

While a certain degree of inflammation is probably necessary to stimulate angiogenesis, to permit repair of tissue and healing of wounds after cardiac surgery, and to protect the patient from infection during the stay in hospital, there is no doubt that excessive and uncontrolled inflammation is harmful, especially in very young children. ${ }^{43,48}$

Unfortunately, there is no consensus on the adequate definition of the systemic inflammatory reaction syndrome and inflammation-related complications after cardiac surgery in the children. Reliable epidemiological data, therefore, are not available. Nevertheless, postoperative dysfunction of organs associated with uncontrolled inflammation has been reported in children, and recognised as a significant problem carrying a high mortality. ${ }^{43}$

\section{Endothelial damage and the capillary leak syndrome}

The capillary leak syndrome is a common feature after cardiac surgery in children. It is characterised by shift of fluid into the interstitial space, with the development of generalised oedema, pleural effusion, and ascites. ${ }^{56}$ If unrecognised and untreated, the hypovolemic state leads to hypoperfusion of the tissues, and damage to organs. Neonates are particularly at risk of developing the capillary leak syndrome, because they have increased movement of fluid across the capillary membrane, leading to rapid shifts from the intra-vascular to the extra-vascular space. In addition, they have some degree of lymphatic insufficiency. ${ }^{57}$

In neonates undergoing cardiac surgery, factors influencing the postoperative development of the capillary leak syndrome include a preoperative inflammatory state, characterised by activation of complement and leukocytosis, and an enhanced inflammatory response to cardiac surgery, with increased release of histamine and tumour necrosis factor- $\alpha$.

The increased capillary permeability produced by the endothelial damage is the substrate for damage to organs and their dysfunction, as shown in an experimental model of cardiac surgery. ${ }^{24}$ As far as the myocardium is concerned, a clear association exists between systemic and intra-parenchymatous synthesis of tumor necrosis factor- $\alpha$ and the degree of intracellular and interstitial oedema due to the rupture of the cell membrane. ${ }^{25}$ 


\section{The systemic inflammatory response and damage to myocardial cells}

The association between the production of proinflammatory cytokines and the development of myocardial cellular damage in neonates has recently been reported by our group. ${ }^{58}$ Indeed, while cardiac surgery with cardiopulmonary bypass causes significant production of interleukin- 6 and interleukin- 8 in all neonates undergoing the arterial switch operation, those who develop postoperative myocardial dysfunction have higher circulating levels of proinflammatory cytokines than do those without myocardial dysfunction. The correlation between postoperative levels of cytokines and troponin-T suggest a causative relationship between inflammation and myocardial cellular damage.

We recently demonstrated this causative relationship in an animal model. ${ }^{25}$

\section{Transient postoperative arrhythmia}

Mediators such as histamine not only have inflammatory properties, but also act as potent arrhythmogenic substances. ${ }^{59}$ Histamine is released during cardiopulmonary bypass from mast cells and circulating basophil leukocytes, both targets for a large number of inflammatory mediators such as complement anaphylatoxins and cytokines. Histamine increases sinus rate, produces various degrees of atrioventricular block, and enhances the automaticity of ectopic pacemakers. ${ }^{60} \mathrm{~A}$ large number of experimental studies have demonstrated that histamine induces sinus tachycardia, junctional ectopic tachycardia, and ventricular tachycardia, and that these effects are mediated through its $\mathrm{H}_{2}$-receptors. ${ }^{59}$

Transient postoperative arrhythmias, such as junctional ectopic tachycardia, which classically occur after cardiac surgery involving cardiopulmonary bypass, are serious complications of surgery for congenital cardiac defects. ${ }^{61}$ Junctional ectopic tachycardia is particularly poorly tolerated in patients with reduced diastolic function, as it leads to reduced ventricular filling, and to the loss of the sequential atrioventricular activity.

We suggested that the development of transient arrhythmias, mainly junctional ectopic tachycardia, after cardiac surgery in children could be related to intraoperative liberation of histamine. ${ }^{48}$ We also confirmed the relationship between systemic inflammation and the occurrence of accelerated nodal rhythms, including junctional ectopic tachycardia, after cardiac surgery. Indeed, in a consecutive cohort of 113 children undergoing cardiac surgery with cardiopulmonary bypass, concentrations of interleukin- 6 were measured in the blood, and interpreted as a marker of

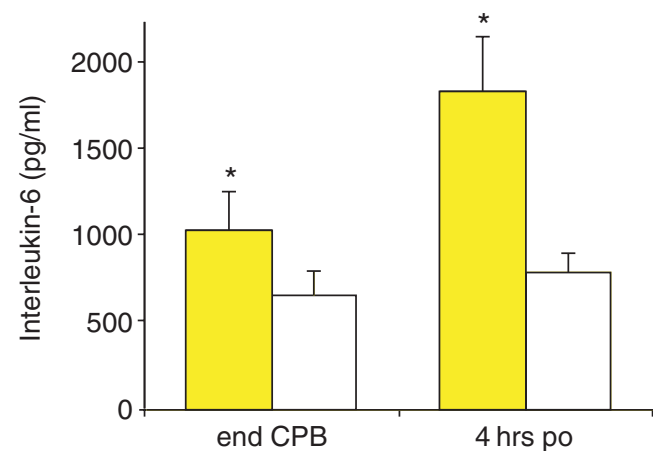

Figure 6.

Plasma concentrations of interleukin-6 measured at the end of cardiopulmonary bypass and 4 hours postoperatively in 113 infants and children having undergone cardiac surgery. Concentrations of interleukin-6 are significantly higher in the 33 patients with accelerated junctional rhythm (yellow) than in the 80 without this complication (white). Results are shown as mean \pm standard error of the mean; ${ }^{*} p<0.05$ between patients with or without accelerated junctional rbythm (Mann-Whitney test).

systemic inflammation. The 33 patients who developed accelerated nodal rhythms had higher levels of interleukin- 6 immediately after cardiopulmonary bypass and 4 hours postoperatively than did the 80 children who did not show this complication (Fig. 6).

Prospective randomised trials should be undertaken to test the hypothesis that histamine antagonists, such as the blockers cimetidine or ranitidine, the latter showing structural similarity with amiodarone, ${ }^{62}$ would be efficient and safe for the prevention of rapid nodal rhythms after cardiac surgery in children.

\section{Failure of multiple systems of organs}

Since inflammatory mediators potentially target all circulating and parenchymatous cells, an uncontrolled systemic inflammatory reaction will manifest itself clinically as multiple failure of organs, a syndrome observed in the setting of sepsis, trauma, and major surgery. ${ }^{63}$ Cardiac operations with cardiopulmonary bypass are representative of this latter category.

In a study designed to analyse the relationship between the systemic inflammatory reaction related to cardiac surgery and the development of postoperative failure of multiple organs, activation of complement, and release of leukocyte elastase were higher in children who developed organ failure than in the others. ${ }^{43}$ Patients with failure of multiple organs all had acute renal and hepatic failure, in addition to cardiovascular insufficiency, thrombocytopenia, disorders of coagulation, and temperatures higher than 39 degrees centigrade. Most of them also had transient 
arrhythmias such as junctional ectopic tachycardia, respiratory insufficiency, and neurological morbidity. In accordance with the high mortality known to be related to the failure of multiple organs, one-third of our patients with this syndrome died postoperatively.

\section{Prophylactics and treatment}

There is, as yet, no specific treatment of the uncontrolled systemic inflammatory response syndrome. A modulation of this response, nonetheless, can be achieved by appropriate pharmacological and technical strategies during the perioperative management. These strategies are aimed at enhancing the balance in favour of the anti-inflammatory response to cardiac surgery, either by decreasing the production of pro-inflammatory mediators or removing them from the circulation, or by enhancing the production of the anti-inflammatory mediators.

\section{Decreasing the production of pro- inflammatory mediators}

Since the primary force of the systemic inflammatory reaction elicited by cardiac surgery is activation of complement,${ }^{64}$ it is tempting to inhibit the complex cascade of events which ensues at its first step. This can be achieved by nonspecific or specific inhibitiors of the complement system.

Donors of nitric oxide, such as sodium nitroprusside, have been shown experimentally to possess properties that inhibit complement, probably by inhibiting $\mathrm{C} 3$-conversion. ${ }^{65}$ In a previous study, we showed that children given low doses of sodium nitroprusside, $1 \mu \mathrm{g} / \mathrm{kg}$ body weight/minute, during cardiopulmonary bypass had lower degrees of activation of complement during and after cardiac surgery, and also lower postoperative morbidity, than those who were not treated in this fashion. ${ }^{65}$

The inhibitor of C1-esterase controls the early phase of the activation of the classical pathway of the complement system, and also inhibits the Hageman factor, coagulation factor $\mathrm{X}$, and fibrinolysis. ${ }^{41}$ Although we did not find any difference in the concentrations of the inhibitor in neonates with and without capillary leak syndrome, ${ }^{56}$ Tassani and collaborators reported improved pulmonary function in patients receiving the inhibitor before the operation. ${ }^{66}$ Due to its antifibrinolytic properties, which could enhance the potential for postoperative thrombosis, the inhibitor of $\mathrm{C} 1$ esterase should be utilised with caution in small infants.

The recombinant soluble complement receptor type 1 , which inhibits the binding of complement fragment $\mathrm{C} 3$ to its receptor, might be useful in mitigating the systemic inflammatory response after cardiac surgery. ${ }^{67}$

Heparin-coated circuits have been shown to increase biocompatibility by attenuating the activation of complement and stimulation of neutrophils. ${ }^{68}$ Few open trials have suggested that they might improve output of urine and oxygenation in the early postoperative period. ${ }^{69}$ Postoperative morbidity and mortality, however, are not significantly reduced. ${ }^{70}$

Serine protease inhibitors such as aprotinin have been claimed to decrease the inflammatory response to cardiac surgery in adults. ${ }^{71}$ This effect, as yet, has not been confirmed in children. ${ }^{72}$

Vitamin $\mathrm{C}$ and $\mathrm{N}$-acetylcysteine act as scavengers of free radicals. As such, they might decrease the neutrophil oxidative burst during cardiac surgery. ${ }^{73,74}$

\section{Removing the inflammatory mediators from the circulation}

Ultrafiltration, introduced by Elliott 10 years ago, ${ }^{75}$ has now become standard in the perioperative management of children undergoing cardiac surgery. In addition to its beneficial effects in removing fluids, which are associated with improved hemodynamics, ultrafiltration is also thought possibly to remove inflammatory mediators from the circulation. ${ }^{51}$ Peritoneal drainage after cardiac surgery in neonates could also provide dialysis of pro-inflammatory cytokines. ${ }^{76}$

\section{Decreasing the production of pro-inflammatory mediators while increasing that of anti-inflammatory proteins}

Glucocorticosteroids inhibit the synthesis of all inflammatory mediators having nuclear factor kappa B as their transcription factor (see above). Basically, glucocorticosteroids act by binding glucocorticoid response elements on glucocorticoid-responsive genes, thereby increasing the transcription of many antiinflammatory proteins such as interleukin-10, interleukin-1 ra, Lipocortin-1, and inhibitory kappa B. ${ }^{6}$ This effect is genomic. Glucocorticoids also repress the expression of many inflammatory genes by inhibiting nuclear factor kappa $\mathrm{B} .{ }^{6}$ This effect is non-genomic.

In adults, glucocorticoids administered before cardiac surgery blunt the production of tumor necrosis factor- $\alpha$ and interleukin- 8 , and increase that of interleukin-10. ${ }^{30}$ In children, the administration of dexamethasone at $1 \mathrm{mg} / \mathrm{kg}$ body weight reduces the production of tumour necrosis factor- $\alpha$ and interleukin-6, and produces a substantial improvement in outcome. ${ }^{77}$ 
Moderate hypothermia during cardiopulmonary bypass has been suggested by us to increase the production of interleukin-10 in infants. ${ }^{50}$ This observation was confirmed in an animal model of cardiac surgery, where cooling the circulating blood down to 28 degrees centigrade was associated with increased production of interleukin-10 in blood and parenchymal cells, and with decreased synthesis of tumour necrosis factor- $\alpha .^{24}$ This shift of the inflammatory response toward a net anti-inflammatory reaction was associated with fewer cells dying, and with greater protection of organs. ${ }^{24,25}$

\section{The influence of the preoperative condition}

As stated above, the potential to initiate and to control the systemic inflammatory response depends on individual factors, in which is included the preoperative condition. During cardiac surgery in children, preoperative conditions potentially affecting the systemic inflammatory response to cardiac surgery, in addition to preoperative infection, mainly involve myocardial hypertrophy, myocardial failure, hypoxaemia, or a combination of these factors. ${ }^{23}$

Haemodynamic overload, such as intracardiac left-to-right shunting leading to congestive heart failure or hypoxaemia, stimulates production of nuclear factor kappa B, and therefore induces the pro-inflammatory cytokines. ${ }^{78,79}$ Circulating levels of interleukin- 6 are abnormally elevated in infants with hypoxaemia or heart failure scheduled for primary cardiac surgery, the former having the highest concentrations that correlate inversely with preoperative arterial saturations of oxygen. ${ }^{23}$ After the operation, levels of interleukin-6 remain higher in patients with preoperative hypoxaemia, indicating a priming of immune competent cells by hypoxaemia that is possibly responsible for the enhanced inflammatory response to cardiac surgery seen in those patients. ${ }^{23}$ The atrial and the ventricular myocardium of infants requiring cardiac surgery with cardiopulmonary bypass also contain substantial amounts of cytokines, which could well increase intramyocardial inflammation in response to surgery, and therefore contribute to perioperative myocardial damage. ${ }^{58}$

\section{Summary and outlook}

Cardiac surgery involving cardiopulmonary bypass in children is related to a systemic inflammatory response that comprises activation of complement, stimulation and degranulation of leucocytes, synthesis of cytokines, and increased interactions between the leucocytes and the endothelium. Contact between blood and foreign surfaces during cardiopulmonary bypass, and ischemia-reperfusion injury, are probably the main inductors of this complex reaction of the organism, primarily acting as a mechanism of homeostasis. Due to reasons as yet unclarified, the systemic inflammatory reaction can become uncontrolled, and then becomes the direct cause of specific postoperative morbidity. Complications, such as the capillary leak syndrome, the multiple organ dysfunction syndrome, and certain types of transient postoperative arrhythmias, are examples for this in neonates and young children.

Technical and pharmacological interventions aimed at modulating, but not completely suppressing, the systemic inflammatory response occurring during cardiac surgery are promising in providing substantial protection for the organs.

Besides the further clarification of the pathophysiological mechanisms contributing to the systemic inflammatory response to cardiac surgery, modulation of the balance between pro- and anti-inflammatory mediators, and stratification of the risk in our population of patients, together with excellent operative and standard postoperative treatment, are mandatory for the achievement of very low postoperative morbidity.

\section{References}

1. Heinrich PC, Castell JV, Andus T. Interleukin-6 and the acute phase response. Biochem J 1990; 265: 621-636.

2. Smith EM, Cadet P, Stefano GB, Opp MR, Hughes TK Jr. IL-10 as a mediator in the HPA axis and brain. J Neuroimmunol 1999; 100: 140-148.

3. Weiler JM. Introduction. In: Whaley K, Loos M, Weiler JM (eds). Complement in health and disease, 2nd edn. Kluwer Academic Publishers, Dordrecht, Boston, London, 1993, pp 1-37.

4. Takabayashi T, Vannier E, Clark BD, et al. A new biologic role for C3a and C3a desArg: regulation of TNF-alpha and IL-1 beta synthesis. J Immunol 1996; 156: 3455-3460.

5. Ertel W, Morrison MH, Ayala A, Chaudry IH. Hypoxemia in the absence of blood loss or significant hypotension causes inflammatory cytokine release. Am J Physiol 1995; 269: R160-R166.

6. Barnes PJ, Karin M. Nuclear factor-kappaB: a pivotal transcription factor in chronic inflammatory diseases. N Engl J Med 1997; 336: 1066-1071.

7. Dinarello CA. Proinflammatory cytokines. Chest 2000; 118: 503-508.

8. Elenkov IJ, Chrousos GP. Stress hormones, proinflammatory and antiinflammatory cytokines, and autoimmunity. Ann N Y Acad Sci 2002; 966: 290-303.

9. Meldrum DR. Tumor necrosis factor in the heart. Am J Physiol 1998; 274: R577-R595.

10. Luheshi GN, Stefferl A, Turnbull AV, et al. Febrile response to tissue inflammation involves both peripheral and brain IL-1 and TNF-alpha in the rat. Am J Physiol 1997; 272: R862-R868.

11. Heuertz RM, Webster RO. Role of C-reactive protein in acute lung injury. Mol Med Today 1997; 3: 539-545.

12. Tilg H, Dinarello CA, Mier JW. IL-6 and APPs: anti-inflammatory and immunosuppressive mediators. Immunol Today 1997; 18: 428-432.

13. Cassatella MA, Meda L, Gasperini S, Calzetti F, Bonora S. Interleukin 10 (IL-10) upregulates IL-1 receptor antagonist 
production from lipopolysaccharide-stimulated human polymorphonuclear leukocytes by delaying mRNA degradation. J Exp Med 1994; 179: 1695-1699.

14. Rennick D, Berg D, Holland G. Interleukin 10: an overview. Prog Growth Factor Res 1992; 4: 207-227.

15. Albelda SM, Smith CW, Ward PA. Adhesion molecules and inflammatory injury. Faseb J 1994; 8: 504-512.

16. Adams DH, Shaw S. Leucocyte-endothelial interactions and regulation of leucocyte migration. Lancet 1994; 343: 831-836.

17. Leist M, Nicotera P. The shape of cell death. Biochem Biophys Res Commun 1997; 236: 1-9.

18. Steller H. Mechanisms and genes of cellular suicide. Science 1995; 267: 1445-1449.

19. Larrick JW, Wright SC. Cytotoxic mechanism of tumor necrosis factor-alpha. Faseb J 1990; 4: 3215-3223.

20. Pinsky MR, Vincent JL, Deviere J, Alegre M, Kahn RJ, Dupont E. Serum cytokine levels in human septic shock. Relation to multiple-system organ failure and mortality. Chest 1993; 103: 565-575.

21. Royall JA, Berkow RL, Beckman JS, Cunningham MK, Matalon S, Freeman BA. Tumor necrosis factor and interleukin 1 alpha increase vascular endothelial permeability. Am J Physiol 1989; 257: L399-L410.

22. Taniguchi T, Koido Y, Aiboshi J, Yamashita T, Suzaki S, Kurokawa A. Change in the ratio of interleukin- 6 to interleukin-10 predicts a poor outcome in patients with systemic inflammatory response syndrome. Crit Care Med 1999; 27: 1262-1264.

23. Hövels-Gürich HH, Schumacher K, Vazquez-Jimenez JF, et al. Cytokine balance in infants undergoing cardiac operation. Ann Thorac Surg 2002; 73: 601-608; discussion 608-609.

24. Qing M, Vazquez-Jimenez JF, Klosterhalfen B, et al. Influence of temperature during cardiopulmonary bypass on leukocyte activation, cytokine balance, and post-operative organ damage. Shock 2001; 15: 372-377.

25. Vazquez-Jimenez JF, Qing M, Hermanns B, et al. Moderate hypothermia during cardiopulmonary bypass reduces myocardial cell damage and myocardial cell death related to cardiac surgery. J Am Coll Cardiol 2001; 38: 1216-1223.

26. van Deventer SJ. Cytokine and cytokine receptor polymorphisms in infectious disease. Intensive Care Med 2000; 26: S98-S102.

27. Verthelyi D, Klinman DM. Sex hormone levels correlate with the activity of cytokine-secreting cells in vivo. Immunology 2000; 100: 384-390.

28. Ma Qing, Schumacher K, Heise R, et al. Intramyocardial synthesis of pro- and anti-inflammatory cytokines in infants with congenital cardiac defects. J Am Coll Cardiol (in press).

29. Ferreiro CR, Chagas AC, Carvalho $\mathbf{M H}$, et al. Influence of hypoxia on nitric oxide synthase activity and gene expression in children with congenital heart disease: a novel pathophysiological adaptive mechanism. Circulation 2001; 103: 2272-2276.

30. Tabardel Y, Duchateau J, Schmartz D, et al. Corticosteroids increase blood interleukin-10 levels during cardiopulmonary bypass in men. Surgery 1996; 119: 76-80.

31. Suberville S, Bellocq A, Fouqueray B, et al. Regulation of interleukin-10 production by beta-adrenergic agonists. Eur J Immunol 1996; 26: 2601-2605.

32. Corbel M, Germain N, Lanchou J, et al. The selective phosphodiesterase 4 inhibitor RP 73-401 reduced matrix metalloproteinase 9 activity and transforming growth factor-beta release during acute lung injury in mice: the role of the balance between Tumor necrosis factor-alpha and interleukin-10. J Pharmacol Exp Ther 2002; 301: 258-265.

33. Wolk K, Docke W, von Baehr V, Volk H, Sabat R. Comparison of monocyte functions after LPS- or IL-10-induced reorientation: importance in clinical immunoparalysis. Pathobiology 1999; 67: 253-256.
34. Adib-Conquy M, Asehnoune K, Moine P, Cavaillon JM. Longterm-impaired expression of nuclear factor-kappa B and I kappa B alpha in peripheral blood mononuclear cells of trauma patients. J Leukoc Biol 2001; 70: 30-38.

35. Volk HD, Reinke P, Krausch D, et al. Monocyte deactivation rationale for a new therapeutic strategy in sepsis. Intensive Care Med 1996; 22: S474-S480.

36. Chenoweth DE, Cooper SW, Hugli TE, Stewart RW, Blackstone EH, Kirklin JW. Complement activation during cardiopulmonary bypass: evidence for generation of $\mathrm{C} 3 \mathrm{a}$ and $\mathrm{C} 5 \mathrm{a}$ anaphylatoxins. N Engl J Med 1981; 304: 497-503.

37. Kirklin JK, Westaby S, Blackstone EH, Kirklin JW, Chenoweth DE, Pacifico AD. Complement and the damaging effects of cardiopulmonary bypass. J Thorac Cardiovasc Surg 1983; 86: 845-857.

38. Hammerschmidt DE, Stroncek DF, Bowers TK, et al. Complement activation and neutropenia occurring during cardiopulmonary bypass. J Thorac Cardiovasc Surg 1981; 81: 370-377.

39. Kirklin JK, Chenoweth DE, Naftel DC, et al. Effects of protamine administration after cardiopulmonary bypass on complement, blood elements, and the hemodynamic state. Ann Thorac Surg 1986; 41: 193-199.

40. Tanaka K, Takao M, Yada I, Yuasa H, Kusagawa M, Deguchi K. Alterations in coagulation and fibrinolysis associated with cardiopulmonary bypass during open heart surgery. J Cardiothorac Anesth 1989; 3: 181-188.

41. Fung M, Loubser PG, Undar A, et al. Inhibition of complement, neutrophil, and platelet activation by an anti-factor D monoclonal antibody in simulated cardiopulmonary bypass circuits. J Thorac Cardiovasc Surg 2001; 122: 113-122.

42. Meri S, Aronen M, Leijala M. Complement activation during cardiopulmonary bypass in children. Complement 1988; 5: 46-54.

43. Seghaye MC, Duchateau J, Grabitz RG, et al. Complement activation during cardiopulmonary bypass in infants and children. Relation to postoperative multiple system organ failure. J Thorac Cardiovasc Surg 1993; 106: 978-987.

44. Seghaye MC, Duchateau J, Grabitz RG, et al. Complement, leukocytes, and leukocyte elastase in full-term neonates undergoing cardiac operation. J Thorac Cardiovasc Surg 1994; 108: 29-36.

45. Vaage J, Valen G. Pathophysiology and mediators of ischemiareperfusion injury with special reference to cardiac surgery. A review. Scand J Thorac Cardiovasc Surg Suppl 1993; 41: 1-18.

46. Tassani P, Barankay A, Haas F, et al. Cardiac surgery with deep hypothermic circulatory arrest produces less systemic inflammatory response than low-flow cardiopulmonary bypass in newborns. J Thorac Cardiovasc Surg 2002; 123: 648-654.

47. Wilson I, Gillinov AM, Curtis WE, et al. Inhibition of neutrophil adherence improves postischemic ventricular performance of the neonatal heart. Circulation 1993; 88: II372-II379.

48. Seghaye MC, Duchateau J, Grabitz RG, et al. Histamine liberation related to cardiopulmonary bypass in children: possible relation to transient postoperative arrhythmias. J Thorac Cardiovasc Surg 1996; 111: 971-981.

49. McBride WT, Armstrong MA, Gilliland H, McMurray TJ. The balance of pro and anti-inflammatory cytokines in plasma and bronchoalveolar lavage (BAL) at paediatric cardiac surgery. Cytokine 1996; 8: 724-729.

50. Seghaye M, Duchateau J, Bruniaux J, et al. Interleukin-10 release related to cardiopulmonary bypass in infants undergoing cardiac operations. J Thorac Cardiovasc Surg 1996; 111: 545-553.

51. Journois D, Israel-Biet D, Pouard P, et al. High-volume, zerobalanced hemofiltration to reduce delayed inflammatory response to cardiopulmonary bypass in children. Anesthesiology 1996; 85: 965-976.

52. Tarnok A, Hambsch J, Schneider P. Cardiopulmonary bypassinduced increase of serum interleukin-10 levels in children. J Thorac Cardiovasc Surg 1998; 115: 475-477. 
53. Jansen NJ, van Oeveren W, Gu YJ, van Vliet MH, Eijsman L, Wildevuur CR. Endotoxin release and tumor necrosis factor formation during cardiopulmonary bypass. Ann Thorac Surg 1992; 54: 744-747; discussion 747-748.

54. Metinko AP, Kunkel SL, Standiford TJ, Strieter RM. Anoxiahyperoxia induces monocyte-derived interleukin-8. J Clin Invest 1992; 90: 791-798.

55. Gormley SM, McBride WT, Armstrong MA, et al. Plasma and urinary cytokine homeostasis and renal function during cardiac surgery without cardiopulmonary bypass. Cytokine 2002; 17 : $61-65$.

56. Seghaye MC, Grabitz RG, Duchateau J, et al. Inflammatory reaction and capillary leak syndrome related to cardiopulmonary bypass in neonates undergoing cardiac operations. J Thorac Cardiovasc Surg 1996; 112: 687-697.

57. Simpson J, Stephenson T. Regulation of extracellular fluid volume in neonates. Early Hum Dev 1993; 34: 179-190.

58. Hövels-Gürich HH, Vazquez-Jimenez JF, Silvestri A, et al. Production of proinflammatory cytokines and myocardial dysfunction after arterial switch operation in neonates with transposition of great arteries. J Thorac Cardiovasc Surg 2002; 124: 811-820.

59. Levi R, Zavecz JH. Acceleration of idioventricular rhythms by histamine in guinea pig heart: mediation by $\mathrm{H} 2$ receptors. Circ Res 1979; 44: 847-855.

60. Levi R, Owen DAA, Trzeciakowski J. Actions of Histamine on the heart and vasculature. In: Granellin CR, Parsons ME (eds). Pharmacology of histamine receptors. Wright, PSG, Bristol, London, Boston, 1998, pp 236-297.

61. Grant JW, Serwer GA, Armstrong BE, Oldham HN, Anderson PA. Junctional tachycardia in infants and children after open heart surgery for congenital heart disease. Am J Cardiol 1987; 59: 1216-1218.

62. Martin D, Lown B. Is amiodarone good for heartburn? Arch Intern Med 1990; 150: 1345-1347.

63. American College of Chest Physicians/Society of Critical Care Medicine Consensus Conference: definitions for sepsis and organ failure and guidelines for the use of innovative therapies in sepsis. Crit Care Med 1992; 20: 864-874.

64. Kalfin RE, Engelman RM, Rousou JA, et al. Induction of interleukin-8 expression during cardiopulmonary bypass. Circulation 1993; 88: II401-II406.

65. Seghaye MC, Duchateau J, Grabitz RG, et al. Effect of sodium nitroprusside on complement activation induced by cardiopulmonary bypass: a clinical and experimental study. J Thorac Cardiovasc Surg 1996; 111: 882-892.
66. Tassani P, Kunkel R, Richter JA, et al. Effect of C1-esteraseinhibitor on capillary leak and inflammatory response syndrome during arterial switch operations in neonates. J Cardiothorac Vasc Anesth 2001; 15: 469-473.

67. Rioux P. TP-10 (AVANT Immunotherapeutics). Curr Opin Investig Drugs 2001; 2: 364-371.

68. Videm V, Mollnes TE, Fosse E, et al. Heparin-coated cardiopulmonary bypass equipment I. Biocompatibility markers and development of complications in a high-risk population. J Thorac Cardiovasc Surg 1999; 117: 794-802.

69. Miyaji K, Hannan RL, Ojito J, Jacobs JP, White JA, Burke RP. Heparin-coated cardiopulmonary bypass circuits: clinical effects in pediatric cardiac surgery. J Card Surg 2000; 15: 194-198.

70. Watanabe H, Miyamura H, Hayashi J, et al. The influence of a heparin-coated oxygenator during cardiopulmonary bypass on postoperative lung oxygenation capacity in pediatric patients with congenital heart anomalies. J Card Surg 1996; 11: 396-401.

71. Murkin JM. Cardiopulmonary bypass and the inflammatory response: a role for serine protease inhibitors? J Cardiothorac Vasc Anesth 1997; 11: 19-23; discussion 24-25.

72. Seghaye MC, Duchateau J, Grabitz RG, et al. Influence of low-dose aprotinin on the inflammatory reaction due to cardiopulmonary bypass in children. Ann Thorac Surg 1996; 61: 1205-1211.

73. Sisto T, Paajanen H, Metsa-Ketela T, Harmoinen A, Nordback I, Tarkka M. Pretreatment with antioxidants and allopurinol diminishes cardiac onset events in coronary artery bypass grafting. Ann Thorac Surg 1995; 59: 1519-1523.

74. Andersen LW, Thiis J, Kharazmi A, Rygg I. The role of $\mathrm{N}$-acetylcystein administration on the oxidative response of neutrophils during cardiopulmonary bypass. Perfusion 1995; 10: $21-26$.

75. Elliott MJ. Ultrafiltration and modified ultrafiltration in pediatric open heart operations. Ann Thorac Surg 1993; 56: 1518-1522.

76. Bokesch PM, Kapural MB, Mossad EB, et al. Do peritoneal catheters remove pro-inflammatory cytokines after cardiopulmonary bypass in neonates? Ann Thorac Surg 2000; 70: 639-643.

77. Bronicki RA, Backer CL, Baden HP, Mavroudis C, Crawford SE, Green TP. Dexamethasone reduces the inflammatory response to cardiopulmonary bypass in children. Ann Thorac Surg 2000; 69: $1490-1495$.

78. Valen G, Yan ZQ, Hansson GK. Nuclear factor kappa B and the heart. J Am Coll Cardiol 2001; 38: 307-314.

79. Wong SC, Fukuchi M, Melnyk P, Rodger I, Giaid A. Induction of cyclooxygenase- 2 and activation of nuclear factor-kappa $B$ in myocardium of patients with congestive heart failure. Circulation 1998; 98: 100-103. 